\title{
江淮地区稻-麦周年产量差及其与资源利用关系
}

\author{
杜祥备 $^{1}$ 习 敏 ${ }^{2}$ 孔令聪 ${ }^{1, *}$ 吴文革 ${ }^{2, *} \quad$ 陈金华 $^{3}$ 许有尊 $^{2}$ 周永进 $^{2}$
}

${ }^{1}$ 安徽省农业科学院作物研究所, 安徽合肥 $230031 ;^{2}$ 安徽省农业科学院水稻研究所, 安徽合肥 $230031 ;^{3}$ 安徽省气象研究中心, 安徽合肥 230031

摘 要: 江淮地区是我国水稻和小麦重要的生产基地, 明确该地区不同产量水平之间的差异特征及形成机制, 探索 区域粮食生产的限制因子, 可为缩减江淮地区周年产量差的技术途径提供科学依据和参考。本研究以稻-麦周年生产 体系为研究对象, 定量分析不同产量水平田块之间的产量差与气候影响因素。结果表明, 江淮地区水稻、小麦及周年 农户水平与试验水平和高产纪录间存在显著的产量差, 分别为 3315.9、1537.5、4645.6 kg hm 和 7498.6、3977.9、 $9840.9 \mathrm{~kg} \mathrm{hm}^{-2}$ 。水稻、小麦及周年农户水平较试验水平还有 $46.2 \% 、 29.7 \%$ 和 $37.3 \%$ 的增产潜力, 较高产纪录还有 $104.5 \% 、 77.0 \%$ 和 $79.0 \%$ 的增产潜力。每穗粒数是造成水稻产量差的主要因子, 穗数和每穗粒数是造成小麦产量差的 主要因子。与农户水平相比, 水稻试验水平和高产纪录的穗粒数分别增加 $30.4 \%$ 和 $116.1 \%$; 小麦试验水平和高产纪 录的穗数和每穗粒数平均分别增加 $40.9 \% 、 70.0 \%$ 和 $21.8 \% 、 19.6 \%$ 。缩小产量差水稻主要依赖于增加每穗粒数, 小麦 靠穗数和每穗粒数的协同提高。生育期累积辐射和积温较低是导致水稻产量差异的主要气候因素, 而生育期降雨过 多是导致小麦产量差异的主要气候因素。根据研究提出了“强稻稳麦”是提升江淮地区周年粮食生产的有效途径。

关键词: 江淮地区; 稻麦两熟; 产量差; 产量潜力; 资源截获

\section{Yield gaps of rice-wheat double cropping and its relationship with resource utilization in Yangtze-Huaihe Rivers region}

DU Xiang-Bei ${ }^{1}$, XI Min ${ }^{2}$, KONG Ling-Cong ${ }^{1, *}$, WU Wen-Ge ${ }^{2, *}$, CHEN Jin-Hua ${ }^{3}$, XU You-Zun ${ }^{2}$, and ZHOU Yong-Jin ${ }^{2}$

\footnotetext{
${ }^{1}$ Crop Research Institute, Anhui Academy of Agricultural Sciences, Hefei 230031, Anhui, China; ${ }^{2}$ Rice Research Institute, Anhui Academy of Agricultural Sciences, Hefei 230031, Anhui, China, ${ }^{3}$ Anhui Province Meteorological Research Institute, Hefei 230031, Anhui, China
}

\begin{abstract}
The Yangtze-Huaihe rivers region is an important production base of rice and wheat in China. It is necessary to clarify the differences and formation mechanism between different yield levels in the region, and to explore the limiting factors for regional grain production, which can provide scientific basis and reference for the management practices to reduce the annual yield gap in the Yangtze-Huaihe rivers region. Based on annual rice-wheat production situation, crop yield was divided into three different levels, farmer yields, experimental yields and high record yields. Yield gaps and the climate factors of different yield levels were quantified. Results showed that there were significant differences between farmer yields and experimental yields, high record yields of rice, wheat and annual in the Yangtze-Huaihe rivers region, which were 3315.9, 1537.5, and 4645.6 kg hm ${ }^{-2}, 7498.6$, 3977.9 , and $9840.9 \mathrm{~kg} \mathrm{hm}^{-2}$, respectively. Compared with the experimental yields, the farmer yields of rice, wheat and annual had yield increase potential of $46.2 \%, 29.7 \%$ and $37.3 \%$, and $104.5 \%, 77.0 \%$ and $79.0 \%$ in comparison with the high record yields, respectively. The number of grains per spike was the main factor resulting in the yield difference in rice, and the grain numbers per spike and the number of spikes contributed to the yield difference in wheat. Compared with the farmer average yield, the grain numbers per spike of rice in experimental yields and high record yields were increased by $30.4 \%$ and $116.1 \%$, respectively; the spikes and grain numbers per spike of wheat were increased by $40.9 \%, 70.0 \%$ and $21.8 \%, 19.6 \%$, respectively. Reducing the yield
\end{abstract}

本研究由国家重点研发计划项目(2017YFD0301306, 2018YFD0300906, 2016YFD0300503)资助。

This study was supported by the National Key Research and Development Program of China (2017YFD0301306, 2018YFD0300906, 2016YFD0300503).

*通信作者(Corresponding authors): 孔令聪, E-mail: konglingcong@126.com; 吴文革, E-mail: aaasrri@163.com

第一作者联系方式: E-mail: duxiangbei@126.com

Received (收稿日期): 2020-04-26; Accepted (接受日期): 2020-08-19; Published online (网络出版日期): 2020-09-21.

URL: https://kns.cnki.net/kcms/detail/11.1809.S.20200921.1148.002.html 
gaps mainly depended on increasing the grain numbers per spike for rice, and synergistic improvement in the number of spikes and the grain numbers per spike for wheat. Cumulative radiation and low accumulated temperature during the growth period were the main climatic factors affected rice production, while excessive rainfall was the main climatic factor affected wheat production. The results suggested that in order to strengthen rice production and stabilize wheat production was an effective way to increase the annual grain production in the Yangtze-Huaihe rivers region.

Keywords: Yangtze-Huaihe Rivers region; rice-wheat double cropping; yield gap; yield potential; resources capture

在当前全球人口膨胀的背景下, 粮食安全问题 日益严峻，预测到 2030 年全球每年粮食需求将达到 28 亿吨。为满足这一需求，提升粮食总产量是未来 农业领域研究的热点问题 ${ }^{[1]}$ 。我国人口对粮食供给 的压力尤为巨大, 在有限的耕地资源背景下, 唯有 提高作物单产水平才是确保粮食安全的唯一途径。

安徽江淮地区地处我国南北气候过渡带，是我国粮 食的主要生产基地之一。稻一麦两熟种植是区域粮食 生产的主要种植制度, 通常水稻于 5 月 10 月至 20 日播种，小麦收获后移栽, 10 月中下旬收获，生育期 140 160 d, 平均单产 $7135.5 \mathrm{~kg} \mathrm{hm}^{-2}$; 小麦 10 月下 旬至 11 月初播种, 5 月底至 6 月初收获, 生育期 200 215 d, 平均单产 $5365.5 \mathrm{~kg} \mathrm{hm}^{-2}$ 。江淮地区常年 稻麦轮作面积 120 万公顷, 占全国稻麦轮作 $25 \%$ 以 上, 为保障国家粮食安全做出了重要贡献 ${ }^{[2]}$ 。

近年来, 安徽粮食生产技术取得长足进步, 连 续十六连丰。但受气候变化、自然灾害及栽培管理 技术等影响, 安徽稻麦单产水平、稳定性与粮食总 产提高面临重大的挑战。现有的生产管理条件下作 物生长潜力仍没有得到充分挖掘, 不同生产主体产 量差距较大，甚至同一地区不同农户田块之间作物 产量的差距也较大。在当前作物单产潜力提升有限 的情况下，通过提高单位土地上的粮食产量来缩减 区域内的产量差变得越来越重要 ${ }^{[3]}$ 。实际生产中江 淮地区稻麦大面积的平均产量还处于较低水平, 单 产还有很大的增长潜力。因此, 缩减区域产量差, 是 全面提高区域粮食生产的关键 ${ }^{[4]}$ 。

产量差研究一直是国际作物学研究的热点。产 量差的研究能够揭示产量的提升空间，及区域产量 提高的限制因子 ${ }^{[1,5-7]}$ 。国内外一些学者从不同侧面 对我国不同区域主要粮食作物产量差及增产潜力进 行了研究 ${ }^{[5-8]}$ 。但以往研究多是针对单一作物进行, 对周年粮食生产和气候资源利用的研究鲜见报道。 同时，针对江淮地区稻麦周年产量差的研究尚未见 报道。本研究结合农户调研和大田试验示范, 定量 分析江淮地区稻-麦周年生产的产量差, 明确区域 粮食产量提升的主要限制因素, 以期为缩减江淮地
区稻-麦周年产量差和粮食总产的持续稳定提高提 供科学依据。

\section{1 材料与方法}

1.1 区域概况

以安徽省江淮地区稻麦两熟主产区为研究区域, 主要包括凤台、寿县、颖上、怀远、定远、凤阳、 天长、霍邱、巢湖、庐江等地区。江淮地区年平均 气温在 $14 \sim 17^{\circ} \mathrm{C}$ 之间, 平均日照 $1800 \sim 2500 \mathrm{~h}$, 平均 无霜期 200 250 d, 平均降水量 800 1800 mm。主要 种植模式是水稻一小麦一年两熟轮作。

\section{2 数据来源}

产量数据主要来源于“十一五”、“十二五”和“十 三五”国家粮食丰产科技工程安徽省代表性地点田 间试验、高产攻关示范和农户生产对照的稻-麦周年 产量数据。其中, 田间试验和高产攻关示范产量数 据水稻季 166 个、小麦季 80 个、周年 72 个，农户 生产对照产量数据水稻季 76 个、小麦季 85 个、周 年 60 个。气象数据来源于安徽省气象局, 包括上述 研究区域的 9 个站点 2008-2019 年逐日的平均温 度、辐射量、降水量等气象资料。

\section{3 产量差的确定}

为比较不同的产量水平，根据 Lobell 等 ${ }^{[1]}$ 的分类 方法，从数据集中选取田间试验和高产攻关示范产 量前 5\%的均值作为高产纪录，中间 $80 \%$ 的均值作为 试验水平，农户产量中间 $80 \%$ 的均值作为农户水平。 确定 3 个不同产量水平: 高产纪录、试验水平和农户 水平。其中水稻高产纪录、试验水平和农户水平数据 分别为 $8 、 133$ 和 61 个, 小麦分别为 $4 、 64$ 和 68 个, 周 年分别为 4、58 和 48 个。根据产量的不同标准水平定 义了 2 个产量差距: 以高产纪录为基础的产量差(YG1) 和基于试验水平为基础的产量差(YG2)。

$\mathrm{YG} 1=$ 高产纪录 - 农户水平, $\mathrm{YG} 2=$ 试验水平农户水平。

\section{4 数据处理}

采用 Microsoft Excel 2019 对数据进行统计与整 理, 用 Origin 2018 进行分析及作图, SPSS 20.0 软件 
进行方差分析, Duncan's 法检验显著性。

\section{2 结果与分析}

\section{1 江淮地区稻-麦周年产量水平}

江淮地区稻-麦两熟种植模式下，水稻、小麦和 周年农户水平分别为 6205.5 9390.0、4177.5 7098.0 和 $11,145.2 \sim 16,335.6 \mathrm{~kg} \mathrm{hm}^{-2}$, 变幅分别为 $7.8 \%$ 、
$11.7 \%$ 和 $10.8 \%$; 水稻、小麦和周年试验水平分别为 9306.4 12,603.0、6000.5 7731.8 和 15,120.0 19,631.4 $\mathrm{kg} \mathrm{hm}^{-2}$, 变幅分别为 $8.7 \% 、 7.9 \%$ 和 $6.3 \%$; 水稻、小 麦和周年高产纪录分别为 $14,379.0 \sim 15,307.5$ 、 $8904.0 \sim 9501.3$ 和 $21,562.5 \sim 22,896.0 \mathrm{~kg} \mathrm{hm}^{-2}$, 变幅分 别为 $2.7 \%$ 、 $1.4 \%$ 和 $2.5 \%$ (图 1)。3 个不同产量层次 中, 高产纪录变幅较小, 农户水平变异较大。
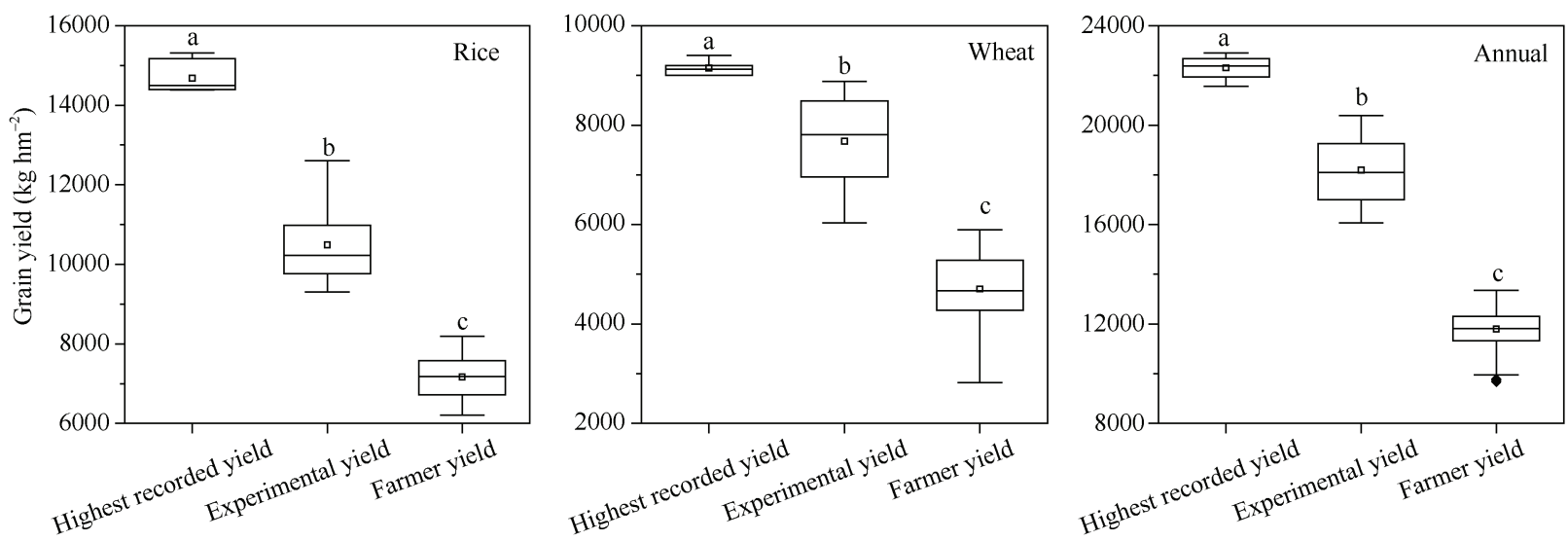

图 1 江淮地区稻-麦周年产量分析

Fig. 1 Descriptive statistics of the rice-wheat annual yield in Yangtze-Huaihe rivers region

不同小写字母表示在 5\%水平差异显著。Values marked with different lowercase letters indicate significant differences at $P<0.05$.

\section{2 江淮地区稻-麦周年产量差}

江淮地区稻-麦两熟种植高产纪录、试验水平与 农户水平之间均存在显著差距(表 1)。其中，水稻、 小麦和周年产量农户水平分别为 7175.4、5168.2 和 $12,463.3 \mathrm{~kg} \mathrm{hm}^{-2}$, 相比试验水平的产量差(YG2)分 别为 $33,315.9 、 1537.5$ 和 $4645.6 \mathrm{~kg} \mathrm{hm}^{-2}$, 相当于试 验水平的 $68.4 \% 、 77.1 \%$ 和 $72.8 \%$, 还有 $46.2 \% 、 29.7 \%$ 和 $37.3 \%$ 的增产潜力; 相比高产纪录的产量差(YG1) 分别为 $7498.6 、 3977.9$ 和 $9840.9 \mathrm{~kg} \mathrm{hm}^{-2}$, 相当于高
产纪录的 $48.9 \%$ 、 $56.5 \%$ 和 $55.9 \%$, 还有 $104.5 \%$ 、 $77.0 \%$ 和 $79.0 \%$ 的增产潜力。

江淮地区稻-麦两熟种植季节间产量差、增产潜 力和增产绝对量均以水稻最高, 小麦相对较小。同 时，高产记录、试验水平与农户水平下水稻产量占 周年产量比重分别为 $65.8 \%$ 、61.3\%和 $57.6 \%$ ，显著 高于小麦的 $34.2 \% 、 38.7 \%$ 和 $42.4 \%$ 。周年总产量越 高, 水稻产量所占比重也越高。因此, 提升水稻季产 量是进一步提高周年产量的关键所在。

表 1 江淮地区稻一麦周年产量、产量差和增产潜力

Table 1 Actual yield, yield potential and yield gaps among different yield levels in Yangtze-Huaihe rivers region

\begin{tabular}{|c|c|c|c|c|}
\hline $\begin{array}{l}\text { 项目 } \\
\text { Item }\end{array}$ & $\begin{array}{c}\text { 产量水平 } \\
\text { Different yield level }\end{array}$ & $\begin{array}{l}\text { 水稻 } \\
\text { Rice }\end{array}$ & $\begin{array}{c}\text { 小麦 } \\
\text { Wheat }\end{array}$ & $\begin{array}{c}\text { 周年 } \\
\text { Annual }\end{array}$ \\
\hline 产量 & 高产纪录 Highest recorded yield & $14,674.1 \mathrm{a}$ & $9146.1 \mathrm{a}$ & $22,304.3 \mathrm{a}$ \\
\hline \multirow[t]{2}{*}{ Yield $\left(\mathrm{kg} \mathrm{hm}^{-2}\right)$} & 试验水平 Experimental yield & $10,491.3 \mathrm{~b}$ & $6705.8 \mathrm{~b}$ & $17,108.9 \mathrm{~b}$ \\
\hline & 农户水平 Farmer yield & $7175.4 \mathrm{c}$ & $5168.2 \mathrm{c}$ & $12,463.3 \mathrm{c}$ \\
\hline 产量差 & 高产纪录-农户水平 Highest recorded yield-Farmer yield (YG1) & 7498.6 & 3977.9 & 9840.9 \\
\hline Yield gap $\left(\mathrm{kg} \mathrm{hm}^{-2}\right)$ & 试验水平-农户水平 Experimental yield-Farmer yield (YG2) & 3315.9 & 1537.5 & 4645.6 \\
\hline 增产潜力 & 农户水平-高产纪录 Farmer yield-Highest recorded yield & 104.5 & 77.0 & 79.0 \\
\hline Increase potential (\%) & 农户水平-试验水平 Farmer yield-Experimental yield & 46.2 & 29.7 & 37.3 \\
\hline
\end{tabular}

表中同列不同小写字母表示在 0.05 水平差异显著。

Values followed by different lowercase letters indicate significant differences in the same column at $P<0.05$. 


\section{3 稻-麦产量与其构成因子间的关系}

将不同产量群体稻麦产量与其构成因子进行相 关分析(图 2)发现, 水稻产量与每穗粒数呈极显著正 相关, 而与穗数和千粒重呈弱的负相关关系。小麦 产量与穗数呈极显著正相关, 与每穗粒数呈显著正 相关，而与千粒重呈弱的正相关关系。进一步分析
与不同产量群体稻麦显著相关的产量构成因子发 现，水稻高产纪录和试验水平均具有显著高的每穗 粒数, 较农户水平分别增加 $116.1 \%$ 和 $30.4 \%$ (表 2)。 小麦高产纪录和试验水平具有显著高的穗数和每 穗粒数，较农户水平分别增加 $70.0 \%$ 、 $40.9 \%$ 和 $19.6 \% 、 21.8 \%$ 。
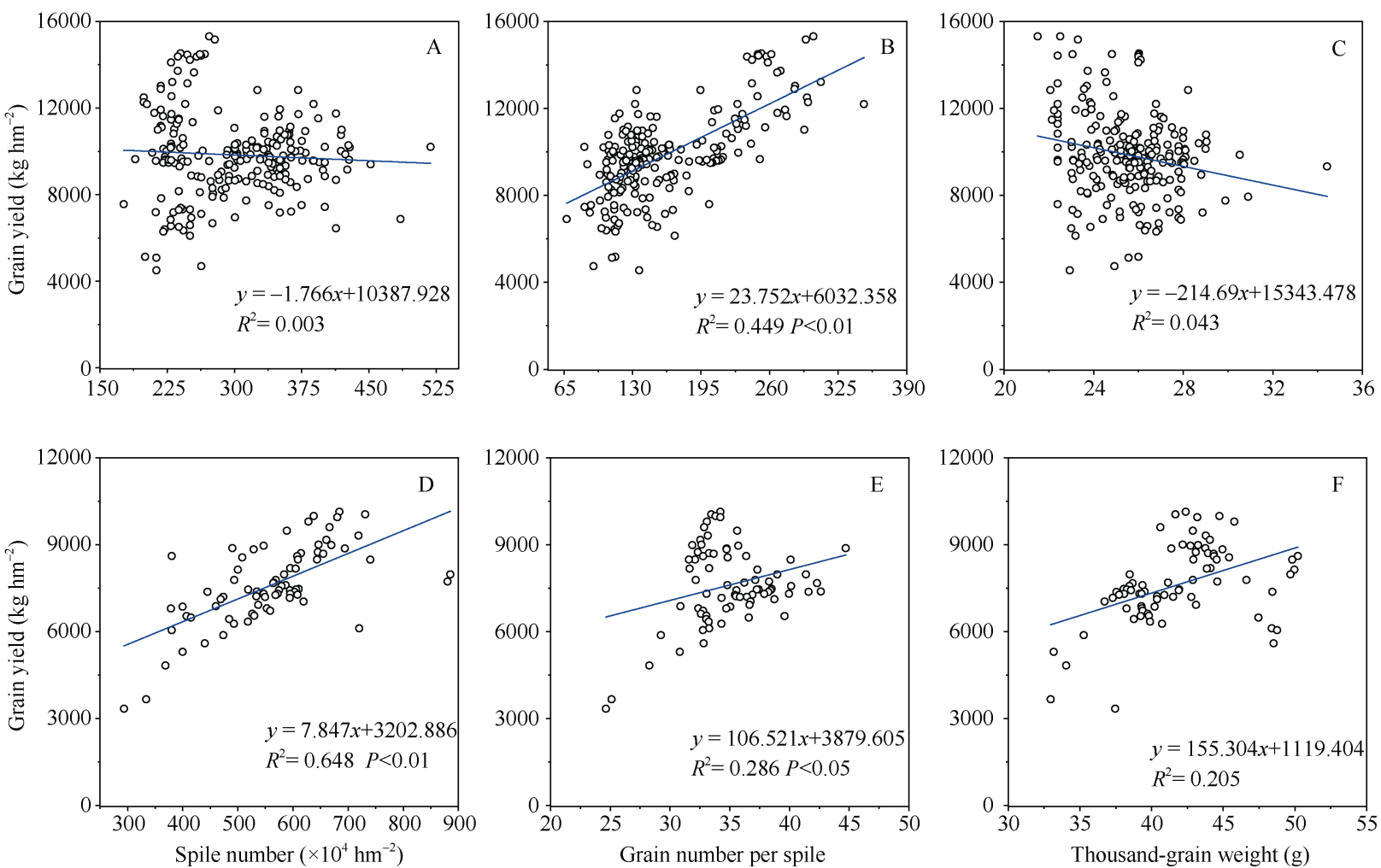

图 2 稻-麦产量与其构成因子间相关性分析

Fig. 2 Relationship between grain yield and its components for different yield levels in Yangtze-Huaihe rivers region

$A 、 B 、 C$ 为水稻, $D 、 E 、 F$ 为小麦。 $A, B, C$ are responsible for rice; $D, E, F$ are responsible for wheat.

表 2 江淮地区稻麦不同产量群体主要产量构成因子差异

Table 2 Differences of key yield components of rice and wheat among different yield levels in Yangtze-Huaihe rivers region

\begin{tabular}{ccccccc}
\hline \multirow{2}{*}{$\begin{array}{c}\text { 项目 } \\
\text { Item }\end{array}$} & \multicolumn{2}{c}{ 水稻 Rice } & \multicolumn{3}{c}{ 小麦 Wheat } \\
\cline { 2 - 7 } & $\begin{array}{c}\text { 每穗粒数 } \\
\text { Grain number } \\
\text { per spike }\end{array}$ & $\begin{array}{c}\text { 相对比例 } \\
\text { Relative ratio } \\
(\%)\end{array}$ & $\begin{array}{c}\text { 穗数 } \\
\text { Spike number } \\
\left(\times 10^{4} \mathrm{hm}^{-2}\right)\end{array}$ & $\begin{array}{c}\text { 相对比例 } \\
\text { Relative ratio } \\
(\%)\end{array}$ & $\begin{array}{c}\text { 每穗粒数 } \\
\text { Grain number } \\
\text { per spike }\end{array}$ & $\begin{array}{c}\text { 相对比例 } \\
\text { Relative ratio } \\
(\%)\end{array}$ \\
\hline 高产纪录 Highest recorded yield & $276.8 \mathrm{a}$ & 216.1 & $43.7 \mathrm{a}$ & 170.0 & $34.1 \mathrm{a}$ & 119.6 \\
试验水平 Experimental yield & $167.1 \mathrm{~b}$ & 130.4 & $36.2 \mathrm{~b}$ & 140.9 & $34.7 \mathrm{a}$ & 121.8 \\
农户水平 Farmer yield & $128.1 \mathrm{c}$ & 100.0 & $25.7 \mathrm{c}$ & 100.0 & $28.5 \mathrm{~b}$ & 100.0 \\
\hline
\end{tabular}

表中同列不同小写字母表示在 0.05 水平差异显著。

Values followed by different lowercase letters indicate significant differences in the same column at $P<0.05$.

\section{4 江淮地区稻-麦生育期气候资源截获}

水稻生育期的总辐射和积温与产量间的变化趋 势明显(图 3-A, C)。相关分析表明，不同产量群体之 间水稻季总辐射和积温差异显著, 表现为高产纪录 $>$ 试验水平>农户水平。说明辐射和积温的高低对水
稻产量起正相关作用。高产记录、试验水平和农户 水平水稻生育期总辐射和积温平均分别为 2791 、 $2562 、 2443 \mathrm{MJ} \mathrm{m}^{-2}$ 和 $4295 、 4114 、 3971^{\circ} \mathrm{C} \mathrm{d}$ 。不同 产量群体水稻生长季的降水无显著变化, 说明水稻 产量与降水相关性不大。 
小麦生育期的总辐射与产量间的变化趋势明显 (图 3-B), 不同产量群体之间差异显著, 表现为高产 纪录>试验水平>农户水平。高产纪录、试验水平和 农户水平小麦生育期总辐射平均分别为 3064、2851、 $2759 \mathrm{MJ} \mathrm{m}^{-2}$, 说明辐射的高低对小麦产量起到正 效应作用。不同产量群体小麦生育期的总积温与产 量间的变化趋势表现为农户水平>试验水平>高产
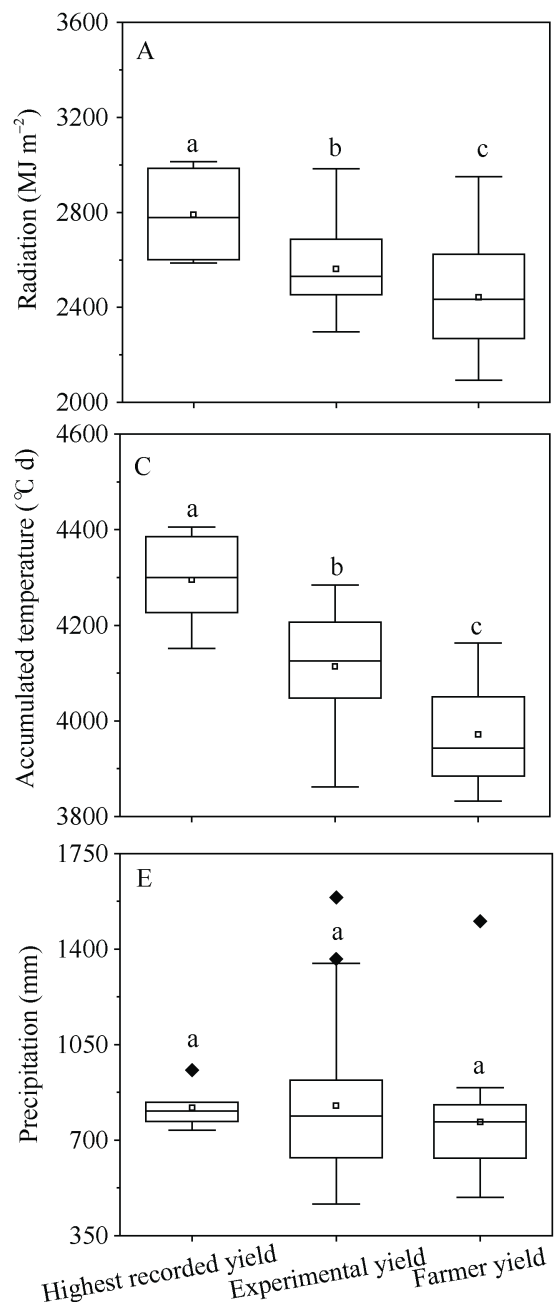

纪录(图 3-D), 降水则表现为农户水平 $>$ 高产纪录> 试验水平(图 3-F), 总积温和降水均与产量呈负相 关关系。

对不同产量群体稻麦生育期进一步分析发现, 高产纪录和试验水平水稻和小麦均具有显著长的生 育期，水稻季较农户水平分别增加了 $8.0 \mathrm{~d}$ 和 $5.9 \mathrm{~d}$, 小麦季分别增加了 $6.4 \mathrm{~d}$ 和 $3.3 \mathrm{~d}$ (表 3 )。

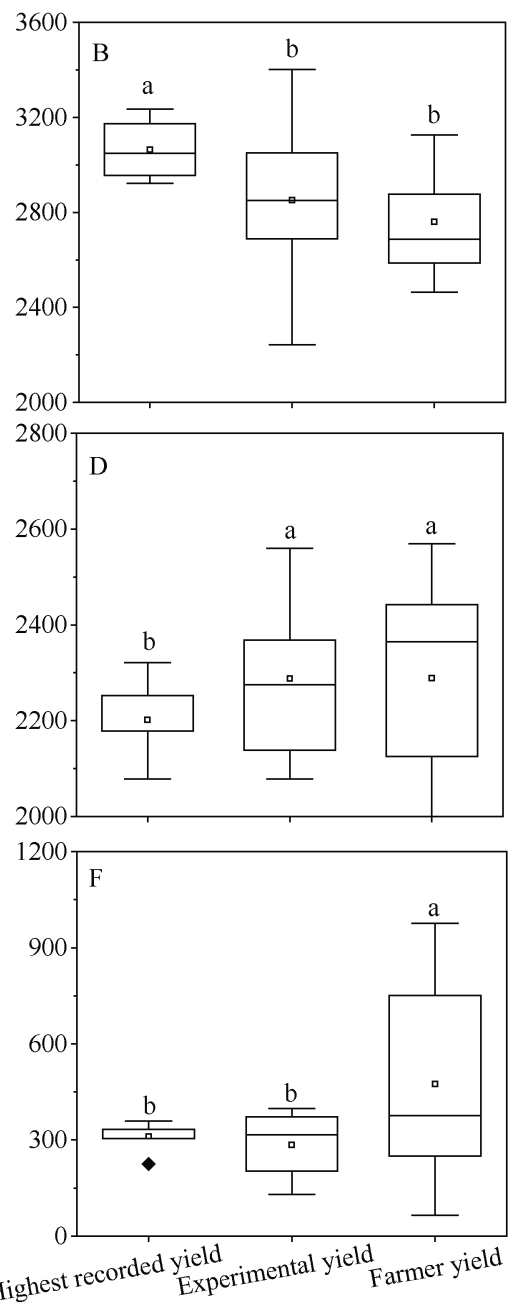

图 3 江淮地区不同稻-麦产量群体生育期气候资源截获

Fig. 3 Accumulated radiation, growth degree-days and precipitation in rice and wheat seasons under different yield levels in Yangtze-Huaihe rivers region

$A 、 C 、 E$ 为水稻, $B 、 D 、 F$ 为小麦。不同小写字母表示在 0.05 水平差异显著。

A, C, E are responsible for rice; B, D, F are responsible for wheat. Values marked with different lowercase letters indicate significant differences at $P<0.05$.

表 3 江淮地区不同稻-麦产量群体生育期

Table 3 Growth period of rice, wheat and annual year under different yield levels in Yangtze-Huaihe rivers region

\begin{tabular}{lcc}
\hline \multicolumn{1}{c}{ 项目 Item } & 水稻 Rice & 小麦 Wheat \\
\hline 高产纪录 Highest recorded yield & $150.3 \mathrm{a}$ & $212.6 \mathrm{a}$ \\
试验水平 Experimental yield & $148.2 \mathrm{a}$ & $209.5 \mathrm{ab}$ \\
农户水平 Farmer yield & $142.3 \mathrm{~b}$ & $206.2 \mathrm{~b}$ \\
\hline
\end{tabular}




\section{3 讨论}

\section{1 江淮地区稻-麦产量差及增产潜力}

分析研究作物产量差与形成特征, 对制定针对 性提高作物产量措施、保障国家粮食安全具有重要 意义 ${ }^{[7]}$ 。本研究通过对安徽江淮地区粮食主产区多 年稻麦生产分析, 定量化了农户水平周年产量相对 于试验水平和高产纪录有 $4645.6 \mathrm{~kg} \mathrm{hm}^{-2}$ 和 9840.9 $\mathrm{kg} \mathrm{hm}^{-2}$ 的增产空间。本研究结果证明了在当前农户 生产条件下, 稻麦产量仍然具有较大的增产空间。 试验水平产量是多年粮丰项目进行试验示范, 是可 以复制, 完全能够达到的产量, 通过进一步缩小农 户水平与试验水平之间的产量差对于整体提高地区 粮食产量有重要的现实意义。本研究结果发现, 农 户水平水稻产量相对于试验水平仍有 $46.2 \%$ 的增产 潜力, 而小麦仅有 $29.7 \%$ 的增产潜力。与小麦比, 水 稻具有较高的产量差、增产潜力和增产绝对量。同时, 水稻产量占周年产量比重显著高于小麦。因此，提高 稻麦周年产量应首先提高水稻产量, “强稻稳麦”是进 一步提高江淮地区稻麦周年粮食生产的主要途径。

\section{2 江淮地区稻-麦产量差的构成因子分析}

稻麦产量是由穗数、每穗粒数和千粒重 3 个构 成因子共同作用的结果。其中单位面积穗数和每穗 粒数被认为是产量形成最重要的决定因素 ${ }^{[9-12]}$ 。本研 究中, 不同产量水平稻麦产量构成因子差异较大。

与前人研究有所不同的是, 本研究发现每穗粒数是 造成水稻产量差异的主要因子。水稻穗数和千粒重 对产量的增加效应较小, 甚至呈负效应, 而每穗粒 数的贡献比较大。这主要是因为在当前生产条件下, 水稻栽培技术不断优化与改进, 水稻育种及机插水 平和种植方式的不断提高, 实际生产中已基本能够 保障基本苗, 改变了以往因穗数不足限制产量提高 的根本因素。同时, 科学合理的肥水管理利于优化 群体质量, 成穗率较高, 穗数已不是限制产量提高 的主要因子 ${ }^{[11,13-14]}$ 。本研究中农民水平已达到 7175.4 $\mathrm{kg} \mathrm{hm}^{-2}$ 较高水平, 穗数与试验水平无显著差异, 但 每穗粒数显著低于试验水平。通过合理的水肥管理, 提高水稻群体颖花量和结实率, 即每穗粒数成为高

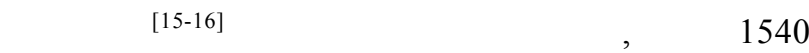
实现高产到超高产是保障足够有效穗数的基础上, 通过增加每穗粒数来实现 ${ }^{[17]}$

江淮地区小麦产量差异的主要原因是穗数和每 穗粒数的不同, 其中穗数与产量间相关系数高于每
穗粒数, 说明穗数对产量的增加效应要高于每穗粒 数。千粒重受品种影响较大, 且与总粒数相互制约, 其对产量的贡献较弱。这与前人研究发现在英国、 阿根廷、墨西哥、澳大利亚等地区, 小麦产量增加 主要归于每穗粒数的提高结果不同 ${ }^{[18-19]}$ 。主要是江 淮地区稻茬小麦生产水平较低, 常常因为播种期降 雨过多, 播期推迟影响出苗质量, 导致冬前有效分 薛少, 造成群体穗数较小, 大穗数少, 产量低下。通 常增加 1 个或多个产量构成因子可以增产 ${ }^{[20-21]}$ 。当 前江淮地区不同产量水平水稻增产途径均依靠增加 每穗粒数, 在足穗的基础上壮大穗, 提高每穗粒数 是产量提高的有效途径。小麦增加穗数和每穗粒数 均能增加产量, 但穗数具有优先性。

3.3 气候条件对江淮地区稻一麦生产潜在产量的 影响

农业生产中光、温、水等气候资源对作物产量 形成有非常重要的作用。前人研究发现, 辐射降低是 华北地区冬小麦夏玉米潜在产量下降的主要因素 ${ }^{[22]}$; 东北地区春玉米在年降水量小于 $500 \mathrm{~mm}$ 的地区, 水分是限制玉米产量的主要限制因子 ${ }^{[23]}$ 。本研究表 明辐射和积温是影响江淮地区水稻产量的重要气象 因素, 降雨不是造成江淮地区水稻产量差异的原因。 水稻只有在最适宜温度下生长才能发挥出最大的潜 在产量, 其产量与生育期累积截获辐射量呈显著正 相关 ${ }^{[24]}$ 。我们前期研究发现, 江淮地区水稻季辐射大 于 $2387.0 \mathrm{MJ} \mathrm{m}^{-2}$, 累积积温达 4003.4 4317.8 ${ }^{\circ} \mathrm{C} \mathrm{d}$, 总降 水量在 466.4 1588.9 mm 范围内可获得 $10,000 \mathrm{~kg} \mathrm{~h}^{-2}$ 以上的产量 ${ }^{[25]}$ 。本研究中农户生产条件下, 降水平 均为 $767 \mathrm{~mm}$ 已满足需求, 辐射平均为 $2443 \mathrm{MJ} \mathrm{m}^{-2}$ 、 积温平均为 $3919^{\circ} \mathrm{C} \mathrm{d}$, 均处于比较低的范围内。可 见, 水稻生育期累积辐射和积温较低是限制其产量 进一步提高的关键因子。我们前期研究发现, 小麦 季辐射在 $2685.0 \sim 3235.2 \mathrm{MJ} \mathrm{m}^{-2}$ 、积温在 1925.0 $2522.6^{\circ} \mathrm{C}$ d、降水在 $245.5 \sim 439.5 \mathrm{~mm}$ 范围内, 可获 得 $8000 \mathrm{~kg} \mathrm{hm}^{-2}$ 以上的产量 ${ }^{[25]}$ 。本研究中农户生产 条件下, 小麦季辐射和积温均已满足高产需求, 但 降水达 $474.4 \mathrm{~mm}$ 超过最适范围, 可见降水量过大、 渍害严重是江淮地区稻茬小麦产量较低的主要原因。

\section{4 江淮地区缩小稻-麦产量差的实现途径}

大量的研究表明, 农户水平相对于试验水平有 较大的产量差主要是由于农户在生产中缺乏理论 指导和调控的针对性, 导致了较差的栽培管理水平 和实际生产的盲目性，这大大限制了作物产量的提 
高 ${ }^{[26-27]}$ 。虽然过去栽培管理措施和技术进步对提高 作物产量贡献巨大，目前栽培管理措施改善的增产 空间依然巨大 ${ }^{[5,28]}$ 。本研究结果同样证明了江淮地区 稻麦的产量潜力仍有较大的增长空间。因此, 如何 进一步缩小产量差, 应作为当前粮食增产的主要途 径 ${ }^{[4]}$ 。根据本研究结果, 缩小水稻产量差主要依赖于 增加每穗粒数, 解决小麦产量差靠穗数和每穗粒数 的协同提高。合理高效的水肥管理、不同种植方式 均能调控资源能促进作物群体结构优化，增加花后 物质生产, 提高收获指数和每穗粒数, 最终实现增 产[29-30]。采用优化的种植模式、耕作和播种技术改 进、适宜的播期和播量、抗逆栽培模式能有效提高 小麦出苗质量, 提高最终穗数 ${ }^{[31-34]}$ 。

在周年生产条件下合理调配季节间的资源优化 配置组合, 从而使温光资源利用最大化，也是提升

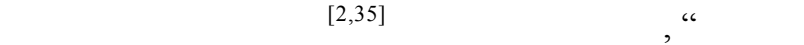
麦”是进一步提高江淮地区稻麦周年粮食生产的最 有效途径, 如何发挥水稻季的高光效和高增产潜力 成为关键 ${ }^{[2]}$ 。通过选用生育期较长的水稻品种，提高 光温资源截获量 ${ }^{[24]}$, 采用周年适宜的稻麦品种搭配 组合 ${ }^{[36]}$ 、尤其是生育期长的晚熟高产水稻品种与耐 迟播早熟高产小麦品种搭配，均可优化周年光温水 资源配置，实现温光资源高效利用。同时水稻和小 麦农耗期立足“抢收”、“抢种”，保证茬口顺利衔接与 温光资源“满负荷”利用，实现稻麦产量和资源利用 效率双提升。

\section{4 结论}

江淮地区稻-麦周年生产存在显著的产量差, 稻麦的产量潜力仍有较大的增长空间, 其中水稻的 增产潜力大于小麦，明确了“强稻稳麦”是提升地区 粮食生产的有效途径。缩小水稻产量差主要依赖于 增加穗粒数, 缩小小麦产量差靠穗数和穗粒数的协 同提高。生育期累积辐射和积温较低是影响水稻产 量差异的主要气候因素, 而生育期降水过多是影响 小麦产量差异的主要气候因素。

\section{References}

[1] Lobell D B, Cassman K G, Field C B. Crop yield caps: their importance, magnitudes, and causes. Annu Rev Environ Resour, 2009, 34: 179-204.

[2] 习敏, 杜祥备, 吴文革, 孔令聪, 陈金华, 岳伟, 许有尊, 周永 进. 稻麦两熟系统适期晚播对周年产量和资源利用效率的影 响. 应用生态学报, 2020, 31: 165-172.

Xi M, Du X B, Wu W G, Kong L C, Chen J H, Yue W, Xu Y Z,
Zhou Y J. Effects of late sowing of two season crops on annual yield and resource use efficiency in rice wheat double cropping system. Chin J Appl Ecol, 2020, 31: 165-172 (in Chinese with English abstract).

[3] De Ponti T, Rijk B, van Ittersum M K. The crop yield gap between organic and conventional agriculture. Agric Syst, 2012, 108: $1-9$.

[4] 刘建刚. 黄淮海农作区冬小麦-夏玉米产量差及其限制因素解 析. 中国农业大学博士学位论文, 北京, 2015.

Liu J G. Yield Gap of Winter Wheat and Summer Maize and Limiting Factors in Huang-Huai-Hai Farming Region. PhD Dissertation of China Agricultural University, Beijing, China, 2015 (in Chinese with English abstract).

[5] Xu X, He P, Zhao S, Qiu S, Johnston A M, Zhou W. Quantification of yield gap and nutrient use efficiency of irrigated rice in China. Field Crops Res, 2016, 186: 58-65.

[6] Chen Y, Wang P, Zhang Z, Tao F, Wei X. Rice yield development and the shrinking yield gaps in China, 1981-2008. Reg Environ Change, 2017, 4: 1-12.

[7] Deng N, Grassini P, Yang H, Huang J, Cassman K G, Peng S. Closing yield gaps for rice self-sufficiency in China. Nat Commun, 2019, 10: 1725.

[8] Zhang T Y, Zhua J, Reiner W M. Responses of rice yields to recent climate change in China: an empirical assessment based on long-term observations at different spatial scales (1981-2005). Agric For Meteorol, 2010, 150: 1128-1137.

[9] Wang Q, Huang J L, He F, Cui K H, Zeng J M, Nie L X, Peng S B. Head rice yield of super hybrid rice Liangyoupeijiu grown under different nitrogen rates. Field Crops Res, 2012, 134: 71-79.

[10] 丁永刚, 李福建, 王亚华, 汤小庆, 杜同庆, 朱敏, 李春燕, 朱 新开, 丁锦峰, 郭文善. 稻茬小麦氮高效品种产量构成和群体 质量特征. 作物学报, 2020, 46: 544-556.

Ding Y G, Li F J, Wang Y H, Tang X Q, Du T Q, Zhu M, Li C Y, Zhu X K, Ding J F, Guo W S. Characteristics of yield components and population quality in high-nitrogen utilization wheat cultivars. Acta Agron Sin, 2020, 46: 544-556 (in Chinese with English abstract).

[11] 卫平洋, 裁实, 唐健, 肖丹丹, 朱盈, 刘国栋, 邢志鹏, 胡雅杰, 郭保卫, 高尚勤, 魏海燕, 张洪程. 安徽沿淮地区优质高产常 规粳稻品种篮选及特征特性. 作物学报, 2020, 46: 571-585. Wei P Y, Qiu S, Tang J, Xiao D D, Zhu Y, Liu G D, Xing Z P, Hu Y J, Guo B W, Gao S Q, Wei H Y, Zhang H C. Screening and characterization of high-quality and high-yield japonica rice varieties in Yanhuai region of Anhui province. Acta Agron Sin, 2020, 46: 571-585 (in Chinese with English abstract).

[12] Reynolds M P, Foulkes M J, Furbank R, Griffiths S, King J, Murchie M, Parry M, Slafer G. Achieving yield gains in wheat. Plant Cell Enviorn, 2012, 35: 1799-1823.

[13] 胡雅杰, 钱海军, 曹伟伟, 邢志鹏, 张洪程, 戴其根, 霍中洋, 许轲, 魏海燕, 郭保卫. 机插方式和密度对不同穗型水稻品种 产量及其构成的影响. 中国水稻科学, 2016, 30: 493-506. Hu Y J, Qian H J, Cao W W, Xing Z P, Zhang H C, Dai Q G, Huo Z Y, Xu K, Wei H Y, Guo B W. Effect of different mechanical transplantation methods and density on yield and its components of different panicle-typed rice. Chin J Rice Sci, 2016, 30: 493-506 (in Chinese with English abstract). 
[14] 韩超, 许方甫, 市金龙, 徐栋, 政实, 赵晨, 朱盈, 刘国栋, 张 洪程, 魏海燕. 淮北地区机械化种植方式对不同生育类型优 质食味粳稻产量及品质的影响. 作物学报, 2018, 44: 1681-1693.

Han C, Xu F P, Bian J L, Xu D, Qiu S, Zhao C, Zhu Y, Liu G D, Zhang H C, Wei H Y. Effects of mechanical planting methods on yield and quality of japonica rice with good taste and different growth durations in Huaibei region. Acta Agron Sin, 2018, 44: 1681-1693 (in Chinese with English abstract).

[15] 郭俊杰, 柴以潚, 李玲, 高丽敏, 谢凯柳, 凌宁, 郭世伟. 江苏 省水稻减肥增产的潜力与机制分析. 中国农业科学, 2019, 52: 849-859.

Guo J J, Chai Y X, Li L, Gao L M, Xie K L, Ling N, Guo S W. The potential and related mechanisms of increasing rice yield by reducing chemical nitrogen application in Jiangsu province. $\mathrm{Sci}$ Agric Sin, 2019, 52: 849-859 (in Chinese with English abstract).

[16] Kobayasi K, Yamane K, Imaki T. Effects of non-structural carbohydrates on spikelet differentiation in rice. Plant Prod Sci, 2001, 4: 9-14.

[17] 吴文革, 习敏, 许有尊, 陈刚, 周永进, 张洪程, 戴其根, 马荣 荣, 王晓燕, 杨飞, 吴晓鹏, 周陶竹, 叶为发, 胡润, 康启中. 籼粳交组合甬优 1540 钵育机插超高产的产量构成及其群体光 合特征. 扬州大学学报(农业与生命科学版), 2017, 38(1): 73-80.

Wu W G, Xi M, Xu Y Z, Chen G, Zhou Y J, Zhang H C, Dai Q G, Ma R R, Wang X Y, Yang F, Wu X P, Zhou T Z, Ye W F, Hu R, Kang Q Z. Population photosynthetic characteristics and yield formation of the mechanically transplanted pot seedlings in hybrid rice variety Yongyou 1540 with super high-yield. J Yangzhou Univ (Agric Life Sci Edn), 2017, 38(1): 73-80 (in Chinese with English abstract).

[18] Gaju O, Reynolds M P, Sparkes D L, Mayes S, Ribas-Vargas G, Crossa J, Foulkes M J. Relationships between physiological traits, grain number and yield potential in a wheat DH population of large spike phenotype. Field Crops Res, 2014, 164: 126-135.

[19] Zhang H, Turner N C, Poole M L. Increasing the harvest index of wheat in the high rainfall zones of southern Australia. Field Crops Res, 2012, 129: 111-123.

[20] Sun Y, Wang X, Wang N, Chen Y L, Zhang S Q. Changes in the yield and associated photosynthetic traits of dry-land winter wheat (Triticum aestivum L.) from the 1940s to the 2010s in Shaanxi province of China. Field Crops Res, 2014, 167: 1-10.

[21] Wu W, Li C J, Ma B L, Shah F, Liu Y, Liao Y C. Genetic progress in wheat yield and associated traits in China since 1945 and future prospects. Euphytica, 2014, 196: 155-168.

[22] Chen C, Baethgen W, Robertson A. Contributions of individual variation in temperature, solar radiation and precipitation to crop yield in the North China Plain, 1961-2003. Clim Change, 2013, 116: 767-788.

[23] Liu Z, Yang X, Hubbard K G, Lin X. Maize potential yields and yield gaps in the changing climate of Northeast China. Global Change Biol, 2012, 18: 3441-3454.

[24] 龚金龙, 邢志鹏, 胡雅杰, 张洪程, 戴其根, 霍中洋, 许轫, 魏 海燕, 高辉. 江淮下游地区籼粳超级稻生育期与温光资源利 用特征的差异研究. 中国水稻科学, 2014, 28: 267-276.

Gong J L, Xing Z P, Hu Y J, Zhang H C, Dai Q G, Huo Z Y, Xu K,
Wei H Y, Gao H. Difference in growth duration and utilization of temperature and solar radiation between indica and japonica super rice in the lower Yangtze and Huaihe river valley. Chin $J$ Rice Sci, 2014, 28: 267-276 (in Chinese with English abstract).

[25] 杜祥备, 孔令聪, 习敏, 吴文革, 陈金华, 岳伟. 江淮区域稻 麦两熟制周年资源分配、利用特征. 中国生态农业学报, 2019, 27: 1078-1087.

Du X B, Kong L C, Xi M, Wu W G, Chen J H, Yue W. Characteristics of resource allocation and utilization of rice-wheat double cropping system in the Jianghuai Area. Chin J Eco-Agric, 2019, 27: 1078-1087 (in Chinese with English abstract).

[26] Boling A A, Tuong T P, van Keulen H, Bouman B A M, Suganda H, Spiertz J H J. Yield gap of rainfed rice in farmers' fields in Central Java, Indonesia. Agric Syst, 2010, 103: 307-315.

[27] Lu C, Fan L. Winter wheat yield potentials and yield gaps in the North China Plain. Field Crops Res, 2013, 143: 98-105.

[28] Mueller N D, Gerber J S, Johnston M, Ray D K, Ramankutty N, Foley J A. Closing yield gaps through nutrient and water management. Nature, 2012, 490: 254-257.

[29] Hawkesford M J. Reducing the reliance on nitrogen fertilizer for wheat production. J Cereal Sci, 2014, 59: 276-283.

[30] Vitantonio-Mazzini L N, Borrás L, Garibaldi L A, Pérez D H, Gallo S, Gambin B L. Management options for reducing maize yield gaps in contrasting sowing dates. Field Crops Res, 2020, 251: 107779.

[31] 赵亚丽, 刘卫玲, 程思贤, 周亚男, 周金龙, 王秀玲, 张谋彪, 王群, 李潮海. 深松(耕)方式对砂姜黑土耕层特性、作物产量 和水分利用效率的影响. 中国农业科学, 2018, 51: 2489-2503. Zhao Y L, Liu W L, Cheng S X, Zhou Y N, Zhou J L, Wang X L, Zhang M B, Wang Q, Li C H. Effects of pattern of deep tillage on topsoil features, yield and water use efficiency in lime concretion black soil. Sci Agric Sin, 2018, 51: 2489-2503 (in Chinese with English abstract).

[32] Mu X Y, Zhao Y L, Liu K, Ji B Y, Guo H B, Xue Z W, Li C H. Responses of soil properties, root growth and crop yield to tillage and crop residue management in a wheat-maize cropping system on the North China Plain. Eur J Agron, 2016, 78: 32-43.

[33] 冯伟, 李世芗, 王永华, 康国章, 段剑钊, 郭天财. 宽幅播种 下带间距对冬小麦衰老进程及产量的影响. 生态学报, 2015, 35: 2686-2694.

Feng W, Li S Y, Wang Y H, Kang G Z, Duan J Z, Guo T C. Effects of spacing intervals on the ageing process and grain yield in winter wheat under wide bed planting methods. Acta Ecol Sin, 2015, 35: 2686-2694 (in Chinese with English abstract).

[34] 贺文畅, 高尚勤, 刘东, 杜祥备, 孔令聪. 沿淮地区水稻一小麦 周年“双高”种植模式. 耕作与栽培, 2018, (5): 57-58.

He W C, Gao S Q, Liu D, Du X B, Kong L C. Rice-wheat annual 'double high' cropping mode along the Huaihe river region in Anhui. Tillage \& Cultivation, 2018, (5): 57-58 (in Chinese with English abstract).

[35] Wang J, Wang E, Yang X, Zhang F, Yin H. Increased yield potential of wheat-maize cropping system in the North China Plain by climate change adaptation. Clim Change, 2012, 113: 825-840.

[36] Du X B, Chen B L, Shen T Y, Zhang Y X, Zhou Z G. Effect of cropping system on radiation use efficiency in double-cropped wheat-cotton. Field Crops Res, 2015, 170: 21-31. 